\title{
ARTIGO
}

DOI: $10.22481 /$ praxis.v13i24.932

\section{A INCLUSÃO DE ALUNOS COM NECESSIDADES EDUCACIONAIS ESPECIAIS NA EDUCAÇÃO DE JOVENS E ADULTOS: ALGUMAS DISCUSSÕES}

\author{
Inclusion of students with sspecial educational needs in the youth and adult education: some \\ discussions
}

La inclusión de alumnos con necesidades educativas especiales en la educación de jóvenes y adultos: algunas discusiones

Keren Talita Silva Miron

Universidade do Estado da Bahia - Brasil

Sônia Maria Alves de Oliveira Reis

Universidade do Estado da Bahia - Brasil

\section{Resumo}

As indagações sobre os desafios e as mudanças ocorridas na Educação de Jovens e Adultos (EJA) com o processo de inclusão de alunos com Necessidades Educacionais Especiais (NEE), resultam das discussões e reflexões feitas por meio do projeto de Iniciação Científica PIBIC/FAPESB. Este texto objetiva compreender como se dá a Inclusão Escolar do aluno da EJA diagnosticado com algum tipo de NEE nas escolas públicas do Município de GuanambiBA. Os estudos de Freire (2013) Cunha (2012) e Mantoan (2006) Contini (2008) e Ferreira (2009) e outros, subsidiaram teoricamente este texto. A compreensão dos dados fundamenta-se nos pressupostos da abordagem qualitativa. Do ponto de vista técnico-metodológico, utilizou-se o questionário e entrevistas visando conhecer o aluno incluído e perceber algumas práticas que facilitam a aprendizagem e algumas que não deveriam ser utilizadas em turmas que têm alunos com NEE. Os resultados da pesquisa reafirma a necessidade de políticas públicas de atendimento à EJA e de formação de professores que atendem alunos da EJA com NEE. O levantamento de dados aponta que é preciso ampliar as discussões neste assunto, pois só assim será possível dizer como melhor incluir estes alunos.

Palavras-Chaves: Educação de Jovens e Adultos. Educação Inclusiva. Políticas públicas.

\begin{abstract}
The questions about the challenges and the changes in Youth and Adult Education (EJA) to the process of inclusion of students with Special Educational Needs (SEN), result from the discussions and reflections made by the Scientific Initiation project PIBIC / FAPESB. This paper aims to understand how is the school inclusion of students of EJA diagnosed with some kind of special needs in public schools in the city of Guanambi-BA. Studies Freire (2013) Wedge (2012)
\end{abstract}


and Mantoan (2006) Contini (2008), and Ferreira (2009) and others theoretically subsidized this text. The data analysis is based on the assumptions of the qualitative approach. Technical and methodological point of view, we used the questionnaire and interviews aimed at knowing the student included and realize some practices that facilitate learning and some that should not be used in classes that have pupils with SEN. The results of the research reaffirms the need for public care policies for adult education and training of teachers who serve students of EJA with SEN. The survey data shows that there is little research focused on the inclusion of pupils with SEN in adult education, so it is necessary to expand the discussions on this subject, because only then you can tell how best to include these students.

Keywords: Youth and Adult Education. Inclusive education. Public policy.

\section{Resumen}

The questions about the challenges and the changes in Youth and Adult Education (EJA) to the process of inclusion of students with Special Educational Needs (SEN), result from the discussions and reflections made by the Scientific Initiation project PIBIC / FAPESB. This paper aims to understand how is the school inclusion of students of EJA diagnosed with some kind of special needs in public schools in the city of Guanambi-BA. Studies Freire (2013) Wedge (2012) and Mantoan (2006) Contini (2008), and Ferreira (2009) and others theoretically subsidized this text. The data analysis is based on the assumptions of the qualitative approach. Technical and methodological point of view, we used the questionnaire and interviews aimed at knowing the student included and realize some practices that facilitate learning and some that should not be used in classes that have pupils with SEN. The results of the research reaffirms the need for public care policies for adult education and training of teachers who serve students of EJA with SEN. The survey data shows that there is little research focused on the inclusion of pupils with SEN in adult education, so it is necessary to expand the discussions on this subject, because only then you can tell how best to include these students.

Palabras clave: Youth and Adult Education. Inclusive education. Public policy.

\section{Iniciando o diálogo}

O presente trabalho é resultado de reflexões realizadas no projeto de Iniciação Científica PIBIC/FAPESB e tem como objetivo compreender e discutir como se dá a Inclusão Escolar do aluno da Educação de Jovens e Adultos (EJA) diagnosticado com algum tipo de Necessidades Educacionais Especiais (NEE) nas escolas públicas do Município de Guanambi-BA.

Os dados da Pesquisa Nacional de Amostra por Domicílio ${ }^{1}$ (PIMENTEL, 2014), apresentam que, em termos de alfabetização, o país ainda precisa abrir espaço para que cerca de 13,3 milhões de brasileiros acima de 15 anos aprendam a ler e escrever. No estado da Bahia, a taxa de analfabetismo é de $16.6 \%$. E, no município de Guanambi, onde realizamos a pesquisa, é

\footnotetext{
${ }^{1}$ PNAD
} 
de 21,7\% (IBGE, 2010). Apesar dos altos índices de analfabetismos identificamos por meio das informações publicadas no censo escolar que houve uma queda no número de matrículas da EJA entre os anos de 2010 à 2014 como podemos observar na tabela a seguir.

Tabela 1: Dados de matrícula da rede municipal de ensino de Guanambi-BA (2010-2014)

\begin{tabular}{|c|c|c|c|}
\hline Ano & $\begin{array}{c}\text { Alunos matriculados na } \\
\text { Educação Básica }\end{array}$ & $\begin{array}{c}\text { Alunos matriculados } \\
\text { na EJA }\end{array}$ & $\begin{array}{c}\text { Alunos matriculados na EJA } \\
\text { com NEE }\end{array}$ \\
\hline 2010 & $\mathbf{2 1 . 0 7 1}$ & $\mathbf{2 . 5 6 9}$ & $\mathbf{5 7}$ \\
\hline 2011 & $\mathbf{2 1 . 2 8 5}$ & $\mathbf{2 . 4 5 4}$ & $\mathbf{3 2}$ \\
\hline 2012 & $\mathbf{2 0 . 3 1 3}$ & $\mathbf{2 . 2 9 8}$ & $\mathbf{4 7}$ \\
\hline 2013 & $\mathbf{2 0 . 4 1 8}$ & $\mathbf{2 . 0 9 8}$ & $\mathbf{3 5}$ \\
\hline 2014 & $\mathbf{2 0 . 5 0 5}$ & $\mathbf{1 . 9 1 6}$ & \\
\hline
\end{tabular}

Fonte: INEP (2010 a 2014)

Os dados do censo escolar disponibilizados no Instituto Nacional de Estudos e Pesquisas Educacionais Anísio Teixeira (INEP) nos possibilitaram conhecer que $2 \%$ dos alunos matriculados na EJA no município de Guanambi no período de 2010 a 2014 possuem algum tipo de NEE na EJA. Além disso, constatamos que no período de cinco anos, houve uma queda de 653 alunos no número de matrículas da EJA. Nesse contexto, questionamos o porquê da diminuição das matrículas e sobre como ocorre o acesso e o atendimento aos alunos da EJA com NEE no município de Guanambi-BA, indagamos em que medida esses jovens e adultos sentia-se incluídos.

O acesso à escolarização é um passo importante para a efetivação do direito a educação inclusiva garantida na legislação aos sujeitos da EJA com NEE. Nesse sentido, à Constituição Federal de 1988 Art. 205 afirma que,

A educação, direito de todos e dever do Estado e da família, será promovida e incentivada com a colaboração da sociedade, visando ao pleno desenvolvimento da pessoa, seu preparo para o exercício da cidadania e sua qualificação para o trabalho. (BRASIL, 1988, Art. 205).

Assim, compreendemos que a matrícula como direito de todos é uma base de sustentação, porém deixamos claro, é uma base e não uma construção em sua totalidade. Pois a inclusão como declara Mantoan (2006) vai muito além do que a massificação do ensino.

Outro aspecto que justifica a relevância desse estudo é o fato de haver um número reduzido de trabalhos que discutem a intercessão dos estudos da Educação de Jovens e Adultos com a 
Educação Inclusiva. Isso pode ser comprovado mediante os resultados das pesquisas apresentadas no GT 18 (Educação de Jovens e Adultos) e no GT 15 (Educação Especial) da Associação Nacional de Pós-Graduação e Pesquisa em Educação (ANPED) e dos trabalhos apresentados e publicados nos Anais do Encontro Nacional de Didática e Prática de Ensino (ENDIPE).

A distribuição da produção acadêmica na Anped e no Endipe no período de 2005 a 2015, mostra que dos 905 trabalhos analisados, 487 reportavam-se a Educação Inclusiva e 418 a Educação de Jovens e Adultos e apenas 6 situa-se no cruzamento de estudos realizados no campo da EJA com os estudos no campo da Educação Inclusiva.

Após análise dos trabalhos apresentados e publicados nos Anais da Anped e do Endipe no período de 2005 a 2015 apresentamos a seguir um quadro com os seis trabalhos que situam-se no cruzamento de estudos realizados no campo da Educação de Jovens e Adultos (EJA) com os estudos no campo da Educação Inclusiva, o que corresponde ao percentual de $1 \%$.

Entretanto, mesmo mediante a relevância das pesquisas encontradas, ponderamos a ausência de estudos que falem sobre o percurso inclusivo da EJA em paralelo à inclusão do aluno com NEE, assim como, trabalhos que discutam o currículo para esses participantes da educação, também investigações sobre como é ou deveria ser o Atendimento Educacional Especializado (AEE) para esses alunos, a presença deles na Sala de Recursos Multifuncionais (SRM), entre outras.

O texto aborda a Educação de Jovens e Adultos e o seu percurso inclusivo. Analisa as Diretrizes Curriculares Nacionais da EJA e proposta curricular do município de Guanambi, discutindo aspectos legais, proposições e efetivação da legislação. Por fim, apresenta algumas experiências escolares de atendimento de alunos da Educação de Jovens e Adultos com Necessidades Educacionais Especiais no município de Guanambi-BA.

Esta pesquisa é predominantemente de cunho qualitativo, pois tem como objetivos compreender o comportamento e a experiência dos humanos por meio da qual se constroem e descrevem significados (BOGDAN; BIKLEN, 1994).

O levantamento de dados dessa investigação foi realizado com os gestores da Rede Municipal de Ensino de Guanambi-BA. Para realizar o levantamento de diferentes experiências de Educação Inclusiva e EJA no município de Guanambi-BA, utilizamos o questionário com gestores das seis instituições de ensino que trabalha com EJA, a fim de verificar como se dá o atendimento, a organização, o funcionamento e a prática de inclusão no cotidiano. $\mathrm{Na}$ oportunidade, solicitamos aos gestores que indicassem as demandas e as necessidades de atendimento mais recorrentes por estes alunos. Além disso, indagamos sobre como é organizado 
o tempo do Atendimento Educacional Especializado (AEE) na EJA, qual a formação dos professores que atuam nesta modalidade de ensino e o que diz o Projeto Político Pedagógico da instituição de ensino sobre os sujeitos da EJA que demandam o AEE.

Além disso, utilizamos a entrevista semiestrutura guiadas por um roteiro de questões previamente elaborado, agendadas com o entrevistado, gravadas e transcritas. Essa escolha se deu por entender que esta possibilita a apropriação de informações concretas, as quais foram oferecidas pelos sujeitos entrevistados. Entrevistamos três coordenadoras pedagógicas cinco diretores e uma professora da SRM.

Realizamos observação no espaço das escolas e em uma SRM, no intuito de identificar se a infraestrutura da escola facilitava ou não o acesso e a circulação dos alunos com NEE. Fizemos análise documental de aspectos da legislação internacional, federal, estadual e municipal. Analisamos também a proposta de educação inclusiva; relatórios dos participantes; projeto político-pedagógico e fichas de alunos.

\section{Educação de Jovens e Adultos e o seu percurso inclusivo}

A educação destinada aos jovens e adultos da sociedade brasileira é uma temática bastante antiga e mesmo que a sua denominação, como afirma Moraes (2007, p.15), "seja recente, a problemática da educação de adultos nos acompanha há muitas décadas".

Sobre o percurso histórico da EJA no Brasil, Aranha (2006) mostra que iniciou-se com a chegada dos jesuítas, logo no período da colonização,

Quando o primeiro governador-geral, Tomé de Souza, chegou ao Brasil em 1549, veio acompanhado por diversos jesuítas encabeçados por Manuel da Nóbrega. Apenas 15 dias depois, os missionários já faziam funcionar, na recémfundada cidade de Salvador, uma escola de "ler e escrever". (ARANHA, 2006, p. 140).

Dessa forma, segundo o autor, percebemos que o caráter educativo no processo de colonização, estava associado à religião, já que os jesuítas tinham a missão de catequizar o povo que se encontrava nas terras exploradas. Ainda sobre a trajetória da EJA no Brasil, os autores Jardilino e Araújo (2014), afirmam que após o processo de colonização, o período imperial é marcado por movimentos republicanos e pela aniquilação do sistema escravocrata. Segundo eles, no período das várias repúblicas, especialmente do século XX, há a busca de "superar a história do desenvolvimento desigual que acompanha a modernidade brasileira e se faz presente em nossa contemporaneidade já quase pós-moderna”. (JARDILINO; ARAÚJO, 2014, p. 43). 
A defesa pela escolarização de adultos intensifica-se com a industrialização e avanços tecnológicos, já que esse desenvolvimento por mais significativo que seja não podia erradicar os problemas sociais de desigualdade enfrentados. Assim, afirmamos que a EJA não fica de fora da construção histórica de um processo vulnerável e instável. No entanto, apesar das marcas de um caráter social desigual, de enfrentamentos desgastantes e de intensas lutas diárias, entendemos que a Educação é um caminho de possibilidades para os jovens e adultos, de muitas conquistas e mudanças advindas da trajetória de vida de cada um e do caminho percorrido no percurso formativo.

Na LDBEN 9.394/96, em seu artigo 37 e inciso primeiro consta que a Educação de Jovens e Adultos será destinada àqueles que não tiveram acesso ou continuidade de estudos no Ensino Fundamental e Médio na idade própria.

$\S 1^{\circ}$ - Os sistemas de ensino assegurarão gratuitamente aos jovens e aos adultos, que não puderam efetuar os estudos na idade regular, oportunidades educacionais apropriadas, consideradas as características do alunado, seus interesses, condições de vida e de trabalho, mediante cursos e exames. (BRASIL, 1996).

A legislação brasileira responsabiliza o poder público e as instituições educacionais a oferecer escolarização àqueles que por algum motivo não tiveram a oportunidade de estudar. Segundo a LDBEN (9394/96) o acesso e a permanência à EJA é um direito e precisa ser garantido aos sujeitos que reivindica uma vaga no sistema educacional.

Jardilino e Araújo (2014) declaram que a EJA deve ser compreendida como um espaço que possibilita olhar político de ressignificação da nossa democracia. Ainda afirmam sobre a importância da luta para desmobilizar o projeto e o discurso neoliberal bem-sucedido presentes atualmente na educação, "a fim de assegurar aos homens e mulheres acesso aos bens sociais que historicamente lhes vêm sendo negado". (JARDILINO; ARAÚJO, 2014, p. 35)

Não olhamos para a Educação como ponte salvadora da humanidade, mas compreendemos que ela de fato é um instrumento de transformação, que "tem como tarefa instrumentalizar criticamente seus cidadãos, construindo e compartilhando conhecimentos" (JARDILINO; ARAÚJO, 2014, p. 98)

Assim, fica evidenciado que o caminho que a EJA deve percorrer é um caminho denso e de muitos enfrentamentos, pois a luta para superar questões como a alta taxa de analfabetismo e invisibilidade dos sujeitos da EJA, é necessária.

Ao pensarmos sobre Educação Inclusiva na EJA devemos compreender o que realmente significa inclusão, pois muitas vezes esta palavra aparece associada a integração de uma forma 
bem incoerente. Mantoan (2006) explica que integração é diferente de inclusão. Para a autora, as palavras são semelhantes em seus significados, porém a realização de suas práticas de inserção "fundamentam em posicionamentos teórico-metodológicos divergentes" (MANTOAN, 2006, p. 17).

Em sua declaração a autora destaca que integração refere-se às inúmeras possibilidades educacionais que garante o acesso do aluno à escola tanto de ensino regular, como especializadas. No entanto, essa inserção se dá parcialmente, pois o sistema e serviços educacionais destinados aos educandos com necessidades educacionais especiais ocorrem de forma segregada.

Já ao que se refere a inclusão, "prevê a inserção do aluno de forma radical, completa e sistemática" (MANTOAN, 2006, p. 19). Nessa direção, a autora além de questionar as políticas e a formação da educação especial e regular, procura um conceito próprio de integração. Para ela, o processo de efetivação da inclusão não se deve atingir apenas o aluno com necessidades, mas a todos os demais que são sujeitos ativos para o sucesso educacional geral.

Laplane e Góes (2007) apresentam um quadro preocupante em relação a inclusão, pois, segundo elas o discurso sobre inclusão muitas vezes não mostra a realidade, apresentando-se mais como uma ideologia. E isso é perceptível desde muito tempo atrás em que o discurso trazia a mensagem de que todos eram iguais, por isso tinham as mesmas oportunidades e o acesso à educação também seria garantido a todos.

Contudo, Laplane e Góes afirmam que ao longo do processo histórico por meio de vários discursos e denúncias se evidenciou que havia uma grande discrepância entre classes, em relação ao direito de igualdade, pois este na prática não era um fato concreto.

Percebemos que os reflexos desse distanciamento do ideal para o real é sentido na atualidade de forma bem direta. Uma vez que, as singularidades dos sujeitos nunca foram compreendidas como um ponto crucial de desenvolvimento, pois como destaca Cunha (2012) o pensamento pedagógico que transcorreu durante o período medieval, iluminismo até chegar à Revolução Industrial estava fundamentado em ir contra a pluralidade e as diferenças, de maneira a tornar as pessoas homogêneas.

Vale destacar que proporcionar uma educação igualitária não deve estar associada a uma educação padronizada, pois se a própria Lei nos afirma que devemos "propiciar continuidade de atendimento até o grau de finalização do atendimento acadêmico (terminalidade) compatível com as suas aptidões” (BRASIL, 1995, p.15), este só poderá ocorrer mediante a compreensão das diferenças. 
Com isso, podemos afirmar uma educação inclusiva não se refere apenas as pessoas com NEE e sim vai muito além. Freire (2013) declara que o homem é um ser inacabado, incompleto, que não sabe de maneira absoluta. Nessa direção, Cunha (2012) enfatiza que em muitos momentos todos precisaremos e temos direito a uma educação que seja inclusiva, pois sempre haverá a necessidade de sermos incluídos em algum momento, em algum lugar, ou necessitaremos de uma atenção maior como possibilidade de aprendizado.

Assim, compreende-se que a Educação Inclusiva está inteiramente voltada à diversidade, pois como Cunha (2012) afirma, somos todos diferentes, não apenas fisicamente, mas com experiências e saberes diferentes. Nesse sentido, se faz necessário,

[...] aceitar as diferenças individuais, valorizar cada ser humano e aprender através da cooperação são outros princípios norteadores da prática da inclusão social que é um processo pelo qual a sociedade procura se adaptar para incluir em seus sistemas gerais pessoas com necessidades educacionais especiais que, por sua vez, preparam-se para assumir seus papéis na sociedade. (CONTINI, 2008, p.3).

Dessa maneira, quando entendemos que as pessoas com NEE na EJA devem "assumir seus papéis na sociedade" compreendemos a importância da aproximação do campo de estudo da Educação de Jovens e Adultos vinculado a Educação Inclusiva.

Para Ferreira (2009), atualmente, os jovens e adultos que apresentam algum tipo de deficiência compõem uma ampla parte da população de analfabetos que não tiveram a possibilidade de acesso, na idade certa, à educação. Ainda, segundo o autor faz-se necessário, "no contexto das profundas desigualdades socioeconômicas e políticas entre grupos sociais, reconhecer os direitos de pessoas com deficiências à EJA constitui ainda um significativo desafio para a sociedade brasileira". (FERREIRA, 2009, p. 75).

Sobre isso, Contini (2008), afirma que a inclusão do aluno com deficiência na EJA não é algo fácil e que há a presença do papel da escola em entender e garantir que este aluno tenha plena participação na escola e consiga atingir o desenvolvimento e a aquisição do conhecimento. Essa realidade justifica a luta pelo ingresso e pela permanência dos alunos na EJA, pois compreendemos que o acesso não significa continuidade, qualificação, condição estável, já que a proporção dos que ingressam na EJA, não é a mesma dos que conseguem concluí-la.

Além disso, Ferreira (2009), nos alerta sobre um grave problema enfrentado pelas pessoas com deficiência matriculadas na EJA que se refere à invisibilidade social. "Institucionalizadas ou mantidas dentro de suas casas, essas pessoas estão impedidas de desfrutar das oportunidades sociais trazidas com a convivência humana" (FERREIRA, 2009, p.78). Segundo o autor, esta 
realidade perdura por muitos séculos e essa ausência da convivência humana, em que a pessoa com deficiência é impossibilitada de vivenciar e experimentar produz o que Ferreira chama de crenças infundadas. $\mathrm{O}$ autor declara que,

[...] pessoas com deficiências são seres humanos e, tanto quanto qualquer outra pessoa sem deficiência, são diferentes entre si: possuem estilos de aprendizagem diferentes, gostam de coisas diferentes, são altos ou baixos, magros ou gordos, são melhores em português ou em matemática, uns possuem linguagem e vocabulário melhor do que outros etc. (FERREIRA, 2009, p. 79)

Assim, como sujeitos únicos e reais devem ser vistos como participantes do mundo social e receberem a oportunidade de estar envolvidos como cidadãos ativos no mundo. $\mathrm{O}$ direito à educação, o acesso, a permanência e o sucesso escolar são as principais formas para alcançar esse objetivo de inserção no mundo.

\section{Reflexões sobre o atendimento do aluno da EJA com NEE na rede municipal de ensino de}

\section{Guanambi-BA}

No período de janeiro a junho de 2016 visitamos seis escolas da Rede Municipal de Educação de Guanambi-BA, que além da Educação Infantil e Ensino Fundamental, oferecem também à EJA. Detectamos uma matrícula de 872 alunos na EJA, desses 246 alunos são do primeiro segmento e 626 alunos são do segundo segmento. No que se refere ao atendimento na EJA de alunos com NEE, não escolarizados, que na idade adulta recorreram à modalidade para iniciar ou continuar os estudos, identificamos 34 alunos, desses, 14 apresentaram laudo médico de NEE, enquanto que 20 apresentam os características, porém não tiveram a oportunidade de fazer uma avaliação com um especialista na área. Constatamos ainda que todas as escolas têm salas de recursos multifuncionais, porém apenas uma delas atende os alunos da EJA.

Com base nos dados expostos, cabe-nos refletir sobre os modos de atendimento na EJA de alunos com alguma NEE, uma vez que a Constituição Federal (1988) afirma que todos têm o direito à educação e ao acesso à escola, sem que haja nenhum tipo de exclusão. Segundo o Art. 3, inciso IV é dever do Estado "promover o bem de todos, sem preconceitos de origem, raça, sexo, cor, idade e quaisquer outras formas de discriminação".

Outro aspecto que nos incomoda se refere às formas de invisibilidade social experimentadas pelos alunos da EJA com NEE, pois como declara Ferreira (2012) estas formas 
podem ser grande geradoras de manifestações exclusão para com a pessoa que apresente alguma deficiência.

Atitudes de preconceito, discriminação, desconhecimento e indiferença em relação às especificidades e as demandas de aprendizagem de alunos da EJA com NEE indicam o quanto precisamos compreender como se dá o processo de inclusão desses alunos nas instituições públicas de ensino. Além disso, se faz necessário conhecer o aluno incluído e perceber algumas práticas educativas que facilitam a aprendizagem e algumas que não deveriam ser utilizadas em turmas que têm alunos com NEE.

De acordo com a legislação internacional e nacional no campo da Educação Especial e Educação Inclusiva todos os sujeitos com NEE independente do curso que está matriculado, precisa ser incluído e de uma educação que atendam suas singularidades.

No que se refere ao ingresso do aluno da EJA com NEE na rede municipal de Guanambi, uma coordenadora da EJA relatou que "o aluno com NEE tem o mesmo direito de matricular na escola que os alunos normais, basta ele procurar a escola é matriculado". (Coordenadora Esmeralda ${ }^{2}$ ). Segundo Esmeralda, vários jovens e adultos com NEE se matriculam na EJA todos os anos, mas pouquíssimos permanecem, por vários motivos, dentre eles infraestrutura inapropriada, falta de formação de professores para atender as demandas de aprendizagem, material didático inadequado, enfim falta de atendimento educacional especializado.

Eu me lembro de que teve uma professora de Mutans ${ }^{3}$ que ela falava, professora Esmeralda o que eu faço? Porque, por exemplo, ela tinha uma cadeirante, mas não dava conta inclusive de ajudar essa cadeirante. A professora não dava conta, e a aluna cadeirante acabou desistindo da escola. Então assim, o acesso, ele está ai, ele acontece, mas a escola acaba não garantindo a permanência pelas condições oferecidas. (Coordenadora Esmeralda).

A fala de Esmeralda nos possibilita pensar como se dá o ingresso dos jovens e adultos com NEE na escola regular e as dificuldades de permanência nela, devido à falta de serviços, recursos e estratégias, como: salas de recursos multifuncionais e atendimento educacional especializado para os alunos da EJA. Relatou ainda que apesar de a legislação brasileira reconhecer a EJA como modalidade de ensino também para as pessoas com deficiência como um direito, percebese que o acesso a serviços e recursos, ainda é frequentemente negado.

Mas por que isso ocorre? Que dificuldades os gestores da rede municipal de educação de Guanambi, professores, funcionários encontram para realizar a EJA numa perspectiva inclusiva?

\footnotetext{
${ }^{2}$ Todos os nomes usados na pesquisa fictícios, a fim de preservar a identidade dos participantes.

${ }^{3}$ Mutans é um distrito do município de Guanambi-BA
} 
Sobre os desafios percebidos em relação à inclusão de alunos com NEE na EJA a diretora Rubi, da Escola Sol, declarou que "do ponto de vista profissional, eu quero estar preparada para receber a todos, para atender a todos, mas eu tenho limitações. Na questão do conhecimento não paro de estudar um único dia, mas mesmo assim aparecem as dificuldades porque a gente sabe que incluir não é o mesmo que adaptar". A entrevistada afirma que muitas vezes as escolas tentam se adaptar para possibilitar a acessibilidade e aquisição do conhecimento, mas reconhecem que são iniciativas tímidas, parciais. Acrescentou que a escola precisa mudar e se adaptar para receber os alunos, mas segundo ela "os alunos precisam se preparar mais ainda para o processo de inclusão”.

Nessa perspectiva Mantoan (2006, p. 18) aborda que "o sistema prevê serviços educacionais segregados. [...]. Em suma: a escola não muda como um todo, mas os alunos têm que mudar para se adaptar às suas exigências". Nesse sentido, compreendemos que a inclusão só acontece de fato quando todos os sujeitos da instituição se comprometem e realizam ações inclusivas. Sobre isso a diretora Jaspe, da Escola Céu, descreve suas angústias sobre a inclusão desses alunos,

$\mathrm{Na}$ verdade nós não estamos prontos pra receber esse aluno. Primeiro recebemos esse aluno para depois nos preocupar com a nossa formação para trabalhar com ele. E a gente tem muitas dificuldades, eu já estive como professora há três anos e trabalhei com uma aluna surda e senti muita dificuldade, não tive apoio, porque não ofertavam cursos de formação para trabalhar e a gente usa o bom senso, conversando com a família e tentando fazer alguma coisa para que aquele aluno aprendesse. Mas nós não tínhamos suporte.

Para Jaspe, um dos desafios fundamentais que emergem da proposta de escola inclusiva para os sujeitos da EJA é a formação do professor, porque o processo educativo inclusivo consiste na criação e no desenvolvimento de "contextos" educativos que possibilitem a interação crítica e criativa entre sujeitos singulares, e não simplesmente na transmissão e na assimilação disciplinar de conceitos e comportamentos estereotipados. Outro aspecto analisado por Jaspe acerca do atendimento aos alunos da EJA com NEE é com relação à avaliação. No processo de inclusão, é necessário que os instrumentos e o conteúdo da avaliação sejam condizentes com as adaptações feitas no currículo, considerando-se as especificidades do aluno com necessidades educacionais especiais.

O como avaliá-lo, como estar trabalhando com essa pessoa, como fazer para que acontecesse a interação, então tínhamos muitas dificuldades. Hoje temos muitas dificuldades, mas lidamos, fomos forçados a aprender a lidar com eles, tivemos que lidar com eles. Mas ainda não são oferecidos formação e creio eu que até na formação acadêmica ainda é pouco [...]. A parte dos componentes curriculares existentes ainda deixa a desejar. [...] eu vejo isso e não é apenas a gente que 
sofre não, o que nos dá menos sofrimento é saber que não é só a gente, mas que precisa fazer alguma coisa. (Diretora Jaspe)

A avaliação é um componente do currículo escolar e considera-se que numa educação inclusiva o currículo precisa passar por uma adaptação. Para que o professor de EJA promova a adaptação curricular de modo a assegurar o atendimento à diversidade existente em sua sala de aula, ele precisa refletir sobre o currículo proposto, questionar os conteúdos existentes e objetivos previamente definidos, tendo como parâmetro a realidade de sua turma.

Porém, isso não significa que cada professor criará um novo currículo a partir do desenvolvimento real observado em sua turma, pois adaptar o currículo não significa propor um currículo diferenciado, mas adequar aquele conteúdo, aquele tempo previsto para aprendizagem à realidade de seu grupo de alunos. A compreensão da existência de diferentes caminhos para a aprendizagem fará com que o professor pense o processo de ensino e busque recursos distintos que favoreçam a aprendizagem, ainda que em tempos diferenciados. Isso requer um profissional embasado teoricamente para justificar as suas decisões e devidamente implicado com a realidade dos seus alunos e com o seu processo de aprendizagem.

Nesse processo, o professor de alunos da EJA com NEE precisa saber potencializar a autonomia, a criatividade e a comunicação dos estudantes, e, por sua vez, tornar-se produtor de seu próprio saber. Muitos professores acreditam que devem receber a preparação para trabalhar com estudantes da EJA com NEE a partir de uma formação inicial que dê a eles autonomia para atuar. Mas também, se verifica que tais processos de formação adquirem sentido, na medida em que se articulam com os saberes que os professores desenvolvem, tendo em vista as suas histórias de vida individual, as suas relações com a sociedade, com a instituição escolar, com os outros atores educativos e os lugares de formação.

Um dos avanços em relação a Educação Inclusiva apontado pelas gestoras entrevistadas refere-se a implementação das Salas de Recursos Multifuncionais (SRM). Todas as seis instituições visitadas possuem SRM implantadas e apenas uma ainda não está funcionando. As cinco SRM ativas possuem profissionais especializados em AEE, que segundo os gestores é uma exigência regulamentada pelo município. No entanto, verificamos que o AEE de alunos da EJA com NEE nas SRM acontece apenas em uma das 6 escolas estudadas.

Sobre o atendimento ou não na SRM dos alunos da EJA com NEE, Safira, a vice-diretora da Escola Estrela, justificou que

[...] achou melhor de atender os alunos da EJA com NEE em uma sala regular para não causar um constrangimento e o aluno poderia até desistir da escola. Então a ideia foi esse aí. Mas as atividades, os professores participam do mesmo 
planejamento, tem as mesmas orientações. Eles não ficam na mesma sala, eles são tirados uma vez na semana das suas aulas, vai duas pessoas, depois mais duas. São do turno noturno, por eles trabalharem, eles são atendido no mesmo turno que estudam.

A Resolução CNE/CEB no 4/2009 orienta que "o AEE deve ser realizado em turno oposto ao da sala de ensino comum, podendo ser feito na própria escola ou em centros de AEE da rede pública ou de instituições comunitárias, confessionais ou filantrópicas sem fins lucrativos". Safira explicou que a legislação recomenda o AEE no turno oposto, mas o fato dos alunos da EJA com NEE serem trabalhadores, portanto impossibilitados de frequentar a escola no turno oposto se organizaram para atendê-los na SRM no mesmo turno que estudam.

É certo que todos os alunos com NEE têm hoje o direito assegurado de frequentar a escola e ter o AEE, mas, só acontecerá o acesso se houver a organização dos tempos e dos espaços escolares. Sobre o AEE, a diretora Topázio, da Escola Lua enfatizou que,

A profissional que trabalha com NEE tem quarenta horas e a escola tem três turnos né, ela atende no caso dois alunos que vem no diurno e ela fez um horário à noite. Só que esse ano a gente ainda não iniciou esse atendimento no noturno. Mas esse atendimento é muito pouco, porque ela tem quarenta horas para atender os três turnos. Ela precisa vir para o noturno para atender os alunos do noturno e na lei está claro que ele precisa ser atendido no contra turno. E eles não vêm. A frequência deles no contra turno é baixa, só tem dois alunos que têm deficiência intelectual que vem para o AEE no contra turno os demais não vem no diurno, entendeu?! E assim, para fazer esse atendimento saindo da sala de aula regular, para ir ser atendido, é complicado. E nem pode, tem que ser atendido no contra turno.

Embora haja na escola outros alunos da EJA que necessitam de AEE, mas o fato de não poderem vir no contra turno são impossibilitados. Nesse sentido a escola faz atendimento especializado apenas a dois alunos. Escola inclusiva pressupõe necessariamente em escola com ensino de qualidade e este ainda é um horizonte a ser alcançado pela sociedade brasileira.

Para se construir uma proposta de inclusão escolar para alunos da EJA com NEE é preciso pensar antes de tudo em como melhorar a escola e o ensino para todos os alunos.

As Diretrizes Curriculares Nacionais para a Educação de Jovens e Adultos (2000) afirmam a necessidade da modalidade estabelecer estratégias para atender de forma diversa, sujeitos em diferentes condições de aprendizagens, respeitando assim as especificidades e realidades da EJA no atendimento de pessoas com NEE.

O Plano Municipal de Educação de Guanambi-BA reconhece a presença de alunos da EJA com NEE, no entanto não há nenhuma meta e estratégias que para atender as singularidades desse sujeitos. 
Além dos inúmeros desafios enfrentados na EJA, encontra-se um grande número de pessoas com necessidades educacionais especiais. As dificuldades visuais são as mais acentuadas nos alunos desse campo educacional. Essas dificuldades interferem diretamente na aprendizagem dos educandos, contribuindo, assim, para o aumento da evasão e repetência nessa modalidade de ensino. (GUANAMBI, 2015).

Nesse contexto Esmeralda sinalizam as angústias de professores frente às demandas de uma EJA numa perspectiva inclusiva.

Um dos problemas que os professores apontam muito é a questão das NEE e a gente não faz nada e não dá conta dessas questões no processo formativo. A gente precisa agregar outras pessoas que possam nos ajudar, mas só o grupo de estudo que a gente tem uma vez a cada mês não dá conta de fazer essas orientações. Principalmente, porque a gente não tem formação para isso e não tem condições também. (Coordenadora Esmeralda).

Para a coordenadora Esmeralda um dos grandes desafios é a formação dos professores para lidar com as demandas de alunos da EJA com NEE e fazer as intervenções. Na condição de formadora de professores de EJA acredita que a inclusão de pessoas com deficiência nos processos institucionais dos vários ambientes, dentre os quais, os escolares requerem, muito além de mudanças pontuais, mas transformações paradigmáticas e culturais no sistema organizacional, assim como o desenvolvimento de concepções, estruturas relacionais e referenciais culturais capazes de agenciarem a complexidade e os conflitos inerentes à interação entre diferentes sujeitos, linguagens, interesses, culturas.

A diretora Jaspe sugere que os encontros de formação e de planejamento mensal da EJA contribua com mais discussões e orientações didáticas sobre a organização do trabalho pedagógico para alunos com NEE,

Eu vejo os meus professores irem para os planejamentos e chegarem aqui com mais angústias. Até porque vem com atividades e não sabem como vão fazer com fulano, sicrano e beltrano, assim, então é complicado. Eu acho que a gente não está pronta para receber, mas tivemos que receber, então, precisamos atendê-lo como se deve. Se não é uma tentativa de inclusão que acaba excluindo, né?(Diretora Jaspe).

Segundo Cunha (2012) muitas escolas que recebem os alunos com NEE, ficam isolados na sala de aula e recebem uma educação segregada uma vez que deveria ser inclusiva. Para o autor, "falta aos profissionais de educação o legítimo entendimento do processo inclusivo, a capacitação para exercer esse papel e, à escola, falta-lhe recursos pedagógicos para proporcionar as condições para a aprendizagem e a inclusão”. (CUNHA, 2012, p. 36) 
Como apresentado a ação inclusiva vai muito além de abrir as portas da escola, pois muitas são as situações em que o aluno com NEE frequenta as aulas, mas é excluído de forma clara e essa exclusão pode ser mais acentuada a depender da deficiência que o aluno possua.

Ainda, sobre a capacitação dos professores, nessa pesquisa pudemos constatar que ela foi apontada como maior responsável pela falta da ação inclusiva no município. Segundo diretora Rubi da Escola Sol que fala sobre como o professor tem lidado com os alunos com NEE,

[...] o professor quer dar o melhor e como ele não consegue, porque ele não está tão preparado, não sabe lidar com essas diferenças, daí ele reclama do despreparo profissional, da falta de condições. O professor fica desesperado quando o aluno não aprende e ele não sabe o que fazer. Aí eu vou na internet busco atividades, a gente senta estuda nos ACCs coletivos, mas é pouco. Nós não estamos amparados com profissionais que nos ajudem que nos orientem. Às vezes, as pessoas dizem que o professor tem que dar conta. Até certo ponto, tem coisa que o professor dá conta, mas ele não é Deus. (Diretora Rubi)

A fala da diretora Rubi suscitam questionamentos e posicionamentos em relação à formação do professor, às diferentes práticas e lugares em que se realizam essas práticas, possibilitando o aprofundamento do debate sobre as ações educacionais, visando assegurar o direito de todas as pessoas à educação escolar inclusiva. Cunha (2014) afirma que não se pode falar sobre inclusão sem se mencionar o papel do professor. Ele apresenta que se faz necessário que o profissional tenha condições de trabalhar com a inclusão e na inclusão, pois de maneira nenhuma será viável o educador ter todos os conhecimentos sobre diferentes dificuldades de aprendizagem e modos de intervenção pedagógica se não consegue incluir seu aluno.

Para ele a inclusão começa primeiramente com a quebra de rótulos e depois com ações de qualidade, pois "quando acreditamos no indivíduo, no seu potencial humano e na sua capacidade de reconstruir seu futuro, o incluímos, e nossa atitude torna-se o movimento que dará início ao processo de emancipação". (CUNHA, 2014, p. 101)

Nesse sentido, percebemos que a ação inclusiva proposta por Cunha, de modo a visar a emancipação desse aluno com NEE é fortalecido quando vemos que o Art. 1 da Lei $\mathrm{N}^{\mathrm{o}}$ 13.146, que declara,

Art. 1ำ É instituída a Lei Brasileira de Inclusão da Pessoa com Deficiência (Estatuto da Pessoa com Deficiência), destinada a assegurar e a promover, em condições de igualdade, o exercício dos direitos e das liberdades fundamentais por pessoa com deficiência, visando à sua inclusão social e cidadania. (BRASIL, 2015)

Assim, incluir o aluno com deficiência é possibilitar que ele possa estar preparado para a vida em sociedade, como um ator social que entende e cumpre o seu papel frente à sua cidadania. Por isso é importante que as instituições não menosprezem ou até mesmo ignorem esses sujeitos, 
mas promovam o seu sucesso não apenas acadêmico e sim o seu desenvolvimento humano e social.

Outro desafio que dificulta a aprendizagem e a inclusão de jovens e adultos com NEE é a falta de suporte pedagógico e recursos humanos especializados.

[...] na escola nós não temos um suporte pedagógico. Tínhamos um coordenador pedagógico que nos ajudava muito, mas foi removido e a gente não tem mais esse profissional que poderia nos ajudar. Então, o professor tem a maior dificuldade para atender alunos com NEE. (Vice-diretora, Safira).

Como foi dito anteriormente, a rede municipal de ensino de Guanambi conta apenas com duas coordenadoras pedagógicas da EJA que tentam dar assistência às seis escolas que atendem a EJA. No entanto, há muita demanda e pouca disponibilidade por parte das coordenadoras devido às diversas atribuições que elas assumem. Sobre isso, a coordenadora Esmeralda relatou que,

Nós não temos dado conta de realizar uma orientação e um acompanhamento específico para todas as turmas de EJA. Então o professor faz o que pode para trabalhar com os alunos. Agora, por exemplo, temos uma aluna cega na EJA, mas quem orienta a professora é uma profissional da rede, especialista em deficiência visual que trabalha também numa SRM. Ela é referencia na rede e dar um suporte importante nessa área com material e orientações pedagógicas específicas e importantes. Os professores que trabalham com alunos surdos também têm orientações pedagógicas, mas os outros, por exemplo, com necessidades intelectuais e físicas, esses a gente não tem ajudado muito. Aí, quando o professor solicita orientações a gente conversa no grupo de estudo. Às vezes, os colegas socializam experiências de como fazem na sala de aula e contam o que deu certo na turma dele. Não temos orientação especifica para os professores de EJA que atendem alunos com NEE, com exceção de quem trabalha com surdos e cegos. (Coordenadora Esmeralda).

A fala de Esmeralda evidencia a necessidade de discutir e refletir na EJA questões teóricas e práticas a respeito da Educação Inclusiva, no lugar onde ela ocorre, suscitando debates sobre o contexto social e a atuação do professor na EJA numa perspectiva inclusiva. Os gestores por meio das entrevistas revelaram os desafios postos à formação de professores no processo de inclusão escolar, ressaltando o quanto os professores se sentem despreparados em sua prática docente no enfrentamento das diferenças cognitivas, sensoriais e físicas que interferem na aprendizagem dos alunos da EJA com NEE.

Daí, a importância de se avaliar os impactos da implementação das políticas públicas de educação especial e inclusão escolar para além da matrícula, posto que as escolas que atendem EJA, não têm acessibilidade arquitetônica, mobiliário e material didático-pedagógicos adequados às necessidades educacionais especiais dos alunos. Os professores, em sua maioria, revelam 
receio ante a inclusão justificado pela suposta falta de preparação prévia para lidar com alunos com deficiência e baixo nível de consciência das possibilidades da própria formação/práxis docente; manifestação inconsciente de atitudes estereotipadas sem resistência à manifestação do preconceito contra os alunos com NEE; ênfase na dimensão conteudista disciplinar.

Dessa forma, constatamos que de diferentes maneiras as escolas municipais do município de Guanambi-BA atende alunos da EJA com NEE no ambiente educacional. A escolarização desses alunos tem desafiado os espaços escolares a construírem novas/outras lógicas de ensino. Diante disso, a formação continuada em processo pode ser uma possibilidade de pensar as demandas escolares e os processos de escolarização dos sujeitos da EJA com NEE. Segundo Nóvoa (1995, p. 25):

A formação não se constrói por acumulação (de cursos, de conhecimentos ou de
técnicas), mas sim através de um trabalho de reflexividade crítica sobre as
práticas e de (re)construção permanente de uma identidade pessoal. Por isso é
tão importante investir a pessoa e dar um estatuto ao saber da experiência [...].
Práticas de formação que tomem como referência as dimensões colectivas
contribuem para a emancipação profissional e para a consolidação de uma
profissão que é autônoma na produção dos seus saberes e dos seus valores.

Entendemos ser fundamental pensar a escola como lócus de formação docente, pois é um espaço que possibilita a construção de mudanças nas práticas pedagógicas, no currículo, no ensino e na aprendizagem dos alunos, inclusive daqueles com NEE, e ainda abre caminhos para que o professor adicione a investigação aos seus saberes-fazeres.

\section{Apontamentos finais}

Constatamos que no munícipio de Guanambi-BA há seis escolas municipais que atendem Educação de Jovens e Adultos, nelas identificamos a presença de 34 alunos com NEE, desses, 14 apresentaram laudo médico, enquanto que 20 apresentam características, porém não foram avaliados por especialistas. Verificamos que as seis escolas possuem SRM, no entanto uma está desativada e apenas em duas escolas é realizado o AEE com os alunos da EJA com NEE.

Além disso, percebemos que o acesso a escolarização se dá mediante a matrícula desses sujeitos nas escolas, porém faltam ações inclusivas estruturadas e que promovam a continuidade e o sucesso desses alunos na vida acadêmica. Observamos que não há uma proposta curricular que viabilize o atendimento inclusivo desses sujeitos, mesmo que estejam presentes nas escolas ainda percebemos modos de invisibilidade e incompreensão sobre como promover inclusão e a aprendizagem. 
Percebemos nas seis instituições estudadas que mesmo não havendo ações de fato inclusivas, há por parte dos professores e gestores um sentimento e uma preocupação em atender e promover a aprendizagem dos educandos da EJA com NEE.

Já ao que se refere a formação inicial e continuada dos professores, contatamos que mesmo havendo reuniões de planejamento mensais com todos os professores que atuam na EJA, não há ações ou projetos que possam permitir ao professor um especialização para compreender o que é inclusão, como ela pode ocorrer ou qual é a postura de um educador inclusivo. Segundo os dados, as experiências de sucesso ou insucesso são compartilhadas apenas no momento de escuta nos encontros, mas nada efetivado ou específico que contemple o aluno da EJA com NEE.

Assim, compreendemos que o município de Guanambi tem possibilitado o ingresso dos alunos da EJA com NEE por meio das matrículas, no entanto, vale lembrar que a inclusão vai além. É preciso pensar em modos que viabilizem a inclusão plena e de qualidade para esses alunos, afim de que eles possam aprender com autonomia, criatividade e, por sua vez torna-se produtor de seu próprio saber. Nesse sentido, os planejamentos, atividades, as propostas curriculares, a infraestrutura deve ser pensada para atendê-los, de maneira a valorizá-los como pessoas e os conhecimentos que trazem.

Nesse contexto, Ferreira (2012, p.79) afirma que "a invisibilidade das pessoas com deficiência gera crenças infundadas, resultado da ignorância geral sobre o que seja 'deficiência' em termos de sua ampla variedade de manifestações, limitações e possibilidades".

Essa afirmação de Ferreira indica o quanto precisamos compreender como se dá o processo de inclusão dos alunos da EJA com NEE nas instituições públicas de ensino. Assim, se faz necessário conhecer o aluno incluído e perceber algumas práticas educativas que facilitam a aprendizagem e algumas que não deveriam ser utilizadas em turmas que têm alunos com NEE.

De acordo com a legislação internacional e nacional no campo da Educação Especial e Educação Inclusiva todos os sujeitos com NEE independente do curso que está matriculado, precisa ser incluído e de uma educação que atendam suas singularidades. E se faz necessário que esse entendimento não seja apenas do professor, mas dos gestores, funcionários administrativos e de serviços gerais e dos próprios estudantes que estudam com os alunos com NEE.

A inclusão não pode ocorrer de forma parcial, ela deve ser uma ação transversal que não se limita apenas ao aluno com NEE. Entender o princípio da ação inclusiva e colocá-lo em prática não é uma tarefa fácil, mas também não é impossível. 


\section{Referências}

ARANHA, Maria Lucia de Arruda. História da educação e da pedagogia geral e Brasil. São Paulo: Moderna, 2006.

ARAÚJO, Luzia C.N. D; MESSIAS, Laura Jane; ASTUTO, Mônica. Surdez e letramento nos anos iniciais para crianças e EJA: uma experiência. In: Anais XIII Encontro Nacional de Didática e Prática de Ensino, 2010, Belo Horizonte. XIV Endipe, 2010.

ASSOLINI, Filomena Elaine Paiva. Professoras alfabetizadoras e suas leituras: história, memória e prática pedagógica escolar. Revista Práxis Educacional, Vitória da Conquista, v. 6, n. 8, jan./jun. 2010. Disponível em: http://periodicos2.uesb.br/index.php/praxis/article/view/616. Acesso em: 14 ago. 2017.

BOGDAN, Robert e BIKLEN, Sari. Investigação Qualitativa em Educação. Portugal: Porto, 1994.

BRASIL. Constituição da República Federativa do Brasil de 1988. Brasília, D.O.U., 5 out. 1998.

BRASIL. Lei de Diretrizes e Bases da Educação Nacional nº 9.394, de 20 de dezembro de 1996. Brasília, 1996.

BRASIL. Plano Nacional de Educação 2014-2024: Lei no 13.005, de 25 de junho de 2014, que aprova o Plano Nacional de Educação (PNE) e dá outras providências. Brasília: Câmara dos Deputados: Edições Câmara, 2014. 86 p. (Série legislação, n. 125). Disponível em: 〈http://www.observatoriodopne.org.br/uploads/reference/file/439/documento-referencia.pdf >. Acesso em: 7 nov. 2015.

BRASIL. Estatuto da Pessoa com Deficiência: Lei n 13.146, de 6 de julho de 2015, que aprova o Estatuto da pessoa com Deficiência e dá outras providências. Brasília: 2015. Disponível em: http://www.planalto.gov.br/CCIVIL_03/_Ato2015-2018/2015/Lei/L13146.htm Acesso em: 7 jul. 2016.

BRASIL. Ministério da Educação e do Desporto. Secretaria de Educação Especial. Subsídios para organização e funcionamento de serviços de educação especial: área de altas habilidades. Brasília, DF, 1995. (Série Diretrizes).

BRASIL. CNE. CEB. Resolução n. 4, de 2 de outubro de 2009, que institui diretrizes operacionais para o atendimento educacional especializado na educação básica, modalidade educação especial. Brasília: 2009.

BRASIL. Parecer CNE/CEB n. 11/2000, de 10 de maio de 2000. Dispõe sobre as Diretrizes Curriculares Nacionais para a Educação de Jovens e Adultos. Conselho nacional de Educação, Ministério da Educação, Poder Executivo, Brasília, DF, 2000. Disponível em: <http://portal.mec.gov.br/cne/arquivos/pdf/PCB11_2000.pdf>. Acesso em: 10 jul. 2016.

CONTINI, Roseli Maria de Fátima. Inclusão de alunos com necessidades educacionais especiais na educação de jovens e adultos. Londrina, 2008. Disponível em: < http://www.diaadiaeducacao.pr.gov.br/portals/pde/arquivos/1861-6.pdf > Acesso em: 17 set 2015. 
CUNHA, Antônio Eugênio. Práticas pedagógicas para a inclusão e diversidade. 2. ed. Rio de Janeiro: Wak Editora, 2012.

CUNHA, Antônio Eugênio. Autismo e inclusão: psicopedagogia e práticas educativas na escola e na família. 5. ed. Rio de Janeiro: Wak Ed, 2014.

EUGÊNIO, Benedito Gonçalves. O currículo na educação de jovens e adultos: entre o formal e o cotidiano numa escola municipal em belo horizonte. Revista Práxis Educacional, Vitória da Conquista, v. 4, n. 4, jan./jun. 2008. Disponível em: https://periodicos2.uesb.br/index.php/praxis/article/view/570. Acesso em: 20 out.2015.

FARIA, Edite Maria da Silva de. O percurso formativo dos professores/pesquisadores da EJA na contemporaneidade. Revista Práxis Educacional, Vitória da Conquista, v. 5, n. 7, jan./jun. 2009. Disponível em: http://periodicos2.uesb.br/index.php/praxis/article/view/607. Acesso em: 20 out.2015.

FERREIRA, Windyz B. EJA e deficiência: estudo sobre a oferta a modalidade EJA para estudantes com deficiência. In AGUIAR, Márcia Ângela (Org.) Educação de Jovens e Adultos: O que dizem as pesquisas? Ministério da Educação/Secretaria de Educação Continuada, Alfabetização e Diversidade - SECAD: Universidade Federal de Pernambuco/Coordenação de Educação a Distância. 2009. Disponível em: www.ufpe.br/cead/index.php?option=com_content\&view. Acesso em 02 de nov. de 2016.

FERREIRA, Windyz B. Construindo uma cultura escolar gentil: clássica educacional inclusiva e superação das manifestações de violência na escola. In: ANDRADE, Fernando César Bezerra de. Escola, faces da violência, faces da paz. João Pessoa/PB. Editora da Universidade Federal da Paraíba. 2012. p. 221-260.

FREIRE, Paulo. Pedagogia da Autonomia. Saberes necessários à prática educativa. 7 ed. São Paulo: Paz e Terra, 2013.

GUANAMBI. Plano Municipal de Educação, Lei n . 951/2015. Diário Oficial do Município de Guanambi-Bahia, Poder Executivo, Guanambi, ano VII, n. 953, 17 jun. 2015.

INSTITUTO BRASILEIRO E GEOGRAFIA E ESTATÍSTICA (IBGE) 2010. Ensino: matrículas, docentes e rede escolar - 2010. IBGE, 2010. Disponível em:

<http://cidades.ibge.gov.br/xtras/grafico_cidades.php?lang=\&codmun=291170\&idtema=117\&se arch=bahia|guanambi|ensino-matriculas-docentes-e-rede-escolar-2012>. Acesso em: 15 maio. 2016.

Instituto Nacional de Educação e Pesquisas Educacionais Anísio Teixeira - INEP (2010 a 2014). Disponível em: http://portal.inep.gov.br/basica-censo. Acesso em: 15 maio 2016.

JARDILINO, José Rubens de Lima; ARAÚJO, Regina Magna Bonifácio de. Educação de jovens e adultos: sujeitos saberes e práticas. São Paulo: Cortez, 2014.

LAPLANE, ADRIANA LIA FRIZMAN; GÓES, MARIA CECÍlIA RAFAEL (Org.). Políticas e práticas da educação inclusiva. 3.ed. Campinas, SP: Autores Associados, 2007. 
MANTOAN, Maria Teresa Eglér. Inclusão escolar: o que é? por quê? como fazer? 2 ed. São Paulo: Moderna, 2006.

MARÍN, Jorge Garcia. Educación y reproducción cultural: el legado de Bourdieu.. Revista Práxis Educacional, Vitória da Conquista, v. 2, n. 2, jan./dez. 2006. Disponível em: https://periodicos2.uesb.br/index.php/praxis/article/view/513. Acesso em: 14 ago. 2017.

MATOS, Selma Norberto; MENDES, Enicéia Gonçalves. A proposta de inclusão escolar no contexto nacional de implementação das políticas educacionais. Revista Práxis Educacional, Vitória da Conquista, v. 10, n. 16, jan./jun. 2014. Disponível em: https://periodicos2.uesb.br/index.php/praxis/article/view/762. Acesso em: 21 out.2015.

MORAES, Salete Campos de. A EJA como espaço de inclusão e empoderamento. In: MORAES, Salete Campos de. Educação especial na EJA: contemplando a diversidade. Porto Alegre, Prefeitura Municipal de Educação, 2007, p. 13-22.

MOURA, Tania Maria de Melo. Formação de educadores de jovens e adultos: realidade, desafios e perspectivas atuais. Revista Práxis Educacional, Vitória da Conquista, v. 5, n. 7, jul./dez. 2009. Disponível em: https://periodicos2.uesb.br/index.php/praxis/article/view/601. Acesso em: 20 out.2015.

NÓVOA, Antônio. Formação de professores e profissão docente. In: NÓVOA, Antonio (Coord.). Os professores e a sua formação. Lisboa: Dom Quixote, 1995.

PEREZ, Marcia Cristina Argenti. Infância e escolarização: discutindo a relação família, escola e as especificidades da infância na escola. Revista Práxis Educacional, Vitória da Conquista, v. 8, n. 12, jan./jun. 2012. Disponível em: http://periodicos2.uesb.br/index.php/praxis/article/view/684. Acesso em: 15 ago. 2017.

PIMENTEL, Jaqueline. Um breve panorama da Pesquisa Nacional por Amostra de Domicílios (PNAD) 2013 (com correções divulgadas pelo IBGE). Rio de Janeiro: Portal DSS Brasil, set. 2014. Disponível em: <http://dssbr.org/site/2014/09/ibge-divulga-pnad-2013/>. Acesso em: 20 out.2015.

REBELO, Piedade Vaz; BORGES, Graciete Franco. Contributos para o estudo do desenvolvimento do adulto: reflexões em torno da generatividade. Revista Práxis Educacional, Vitória da Conquista, v. 5, n. 7, jul./dez. 2009. Disponível em:

https://periodicos2.uesb.br/index.php/praxis/article/view/603. Acesso em: 20 out.2015.

SALES, Sheila Cristina Furtado; COSTA, Gicélia Aparecida Cotrim; OLIVEIRA, Jurenilda Prado. A trajetória da EJA no estado da Bahia: da suplência à aceleração. Revista Práxis

Educacional, Vitória da Conquista, v. 5, n. 7, jul./dez. 2009. Disponível em: https://periodicos2.uesb.br/index.php/praxis/article/view/605. Acesso em: 20 out.2015.

SAMAPIO, Marisa Narcizo. Educação de Jovens e Adultos: uma história de complexidade e tensões. Revista Práxis Educacional, Vitória da Conquista, v. 5, n. 7, jul./dez. 2009. Disponível em: https://periodicos2.uesb.br/index.php/praxis/article/view/600. Acesso em: 20 out.2015.

SANTOS, Katia Silva; BAPTISTA, Claudio Roberto. Novos 'referenciais' cognitivos e normativos para a política nacional de educação especial no Brasil. Revista Práxis 
Educacional, Vitória da Conquista, v. 10, n. 16, jan./jun. 2014. Disponível em: https://periodicos2.uesb.br/index.php/praxis/article/view/760. Acesso em: 20 out.2015.

SANTOS, José Jackson Reis dos. Especificidades dos saberes para a docência na educação de pessoas jovens e adultas. Revista Práxis Educacional, Vitória da Conquista, v. 6, n. 8, jan./jun. 2010. Disponível em: https://periodicos2.uesb.br/index.php/praxis/article/view/623. Acesso em: 20 out.2015.

VENÂNCIO, Carlos Venâncio; GIORGI, Amaral Garboggini Di Giorgi, As séries iniciais da educação de jovens e adultos em nível municipal e as políticas públicas implementadas - em busca de novos significados. Revista Práxis Educacional, Vitória da Conquista, v. 5, n. 7 , jul./dez. 2009. Disponível em: https://periodicos2.uesb.br/index.php/praxis/article/view/606. Acesso em: 20 out.2015.

Keren Talita Silva Miron

Universidade do Estado da Bahia - Brasil Bolsista de PIBIC/FAPESB.

Participa da linha de pesquisa "Educação do campo, Educação de Jovens e Adultos e Movimentos Sociais"

Núcleo de Estudos, Pesquisa e Extensão Paulo Freire (NEPE)

E-mail: keren_talita@hotmail.com

Dr $^{a}$ Sônia Maria Alves de Oliveira Reis Universidade do Estado da Bahia - Brasil Departamento de Educação

Professora do Programa de Pós-Graduação em Educação da Universidade Estadual do Sudoeste da Bahia Coordenadora do Núcleo de Estudos, Pesquisa e Extensão Paulo Freire (NEPE) E-mail: sonia_uneb@hotmail.com

Recebido em: 22 de novembro de 2016 Aprovado em: 17 de dezembro de 2016 